\title{
Sensory profile in children with autism disorder and children with typical development
}

\author{
Rebeca A. Pérez ${ }^{1}$, Germán E. Burguillos-Torres ${ }^{1}$, Victoria G. Castillo-Velásquez¹, \\ Natalia Moreno-Zuleta ${ }^{1}$, Rosa I. Fonseca-Angulo ${ }^{1}$, Cesar Blumtritt ${ }^{1}$, and Rafael García-Jiménez² \\ ${ }^{1}$ Research Group, Foundart Academy, Colombia/Miami. Miami, Florida, United States, ${ }^{2}$ Research Department, Simon Bolivar University. Barranquilla, \\ Colombia
}

\begin{abstract}
Objective: The objective of the study was to compare the sensory profile characteristics of the children with autism spectrum disorder (ASD) and children with typical development (TD) within the ages of 3 and 12 years who attended the rehabilitation center in Barranquilla and Valledupar Colombia. Methods: A study of descriptive type correlation of the sensory profile was conducting using the Short Sensory Profile 2 by Winnie Dunn on boys and girls with an ASD diagnosis and children with a TD. Results: A total of 59 test subjects were included in the study comprised 39 children on the ASD (5 girls and 36 boys) and 28 children with a TD (11 girls and 17 boys). The medium age was 6.97 for the ASD group and 6.61 for the TD group. There are differences in each of the patterns of pre-processing and sensory systems analyzed in children on the ASD and $T D(p<0.05)$ except at the visual system processing level $(p>0.05)$. Conclusions: The study indicates that there is a significant difference in between the ASD group and the TD group, these differences indicate that the population with ASD presents higher level in regard to sensory processing patterns in comparison to TD in accordance to each category in the Short Sensory Profile 2 by Winnie Dunn.
\end{abstract}

Key words: Sensory profile. Autism spectrum child. Neurotypical. Child.

\section{Introduction}

The American Psychiatric Association with acronyms APA ${ }^{1}$ published in 2013, the Diagnostic Manual of Mental Disorders DSM-5 where the Asperger, unspecified developmental disorders, and autism were united in a single diagnostic criterion called autism spectrum disorder (ASD). In this neurodevelopmental disorder, there is a deficit in communication, socialization and the interaction of multiple contexts, as well as restrictive, repetitive patterns of behavior, and restrictions of interest or activities ${ }^{2}$. The prevalence of ASD worldwide is approximately 1-6 per thousand individuals. In the
United States, it is one to every 59 individuals. In Colombia, there are no exact data at present ${ }^{3}$.

Approximately, between $45 \%$ and $96 \%$ of children with ASD $^{4}$ and 11 and $16 \%$ of children with typical development (TD) have sensory processing deficits ${ }^{5}$, however, in Latin American children, it is between 18 and $31 \%{ }^{6}$. This type of alterations was initially defined by Ayres as a sensory integration disorder that consists of an alteration of the functioning of the nervous system due to the fact that the information received through the different senses is not processed adequately and efficiently ${ }^{7,8}$. Giving some kind of sensory integrative dysfunction such as motor restlessness, inadequate

\section{Correspondence:}

Rosa Isabel Fonseca-Angulo

E-mail: rosafonse_2004@ hotmail.com
Available online: $30-10-2019$ Rev Mex Neuroci. 2019;20(5):229-236 www.revmexneurociencia.com

1665-5044/@ 2019. Academia Mexicana de Neurología A.C. Published by Permanyer México. This is an Open Access article under the CC BY-NC-ND license (http://creativecommons.org/licenses/by-nc-nd/4.0/). 
coordination, problems of visual perception, and difficulties in following the rhythm of work in class and others ${ }^{9,10}$.

Subsequently, Miller et al. ${ }^{11}$ proposed the term sensory processing disorder, referring to those individuals who experienced difficulties in the participation of activities of daily life, as a result of alterations in sensory processing. This proposal is divided into three categories: sensory modulation disorder, sensory-based motor disorder, and sensory discrimination disorder. In 1997, Dunn ${ }^{12}$ proposes a new approach in which she poses four patterns of sensory processing that arise from the interaction between the types of thresholds (high or low) and the type of response (agree or against).

Within the patterns of sensory integration is the pattern of low registration, corresponding to the responses of high neurological threshold and a tendency to act passively. That is, the individual within this pattern fails to perceive the same intensity of information of the environment and does not seem any need to satisfy his response (passive). One example of these behaviors is not realize that his face or hands are dirty, leave clothes twisted after going to the bathroom or difficulty to determine the amount of force they should use when doing sports or during fine motor activities ${ }^{12,13}$.

In the search pattern, there are responses against the high neurological threshold, children with this type of pattern require a great intensity of sensory information, which they do not receive from the daily stimuli of their environment, leading them to acquire an active role to counteract its threshold ${ }^{13,14}$. The behaviors of a child with a search pattern correspond precisely to those of a child who presents search for sensations, an example of these behaviors are: the continuous search for movements, seems to be unaware of the danger; constantly looking for or making noise, squeezing objects, touching or embracing others excessively and taking inedible objects to the mouth ${ }^{14}$.

Regarding the sensitivity pattern, children are able to perceive sensations despite the fact that they involve a small amount or intensity of information, becoming simply a kind of "radar" when detecting information, but they do not acquire an active role to counteract its threshold, an example that clearly describes this pattern is the distraction that occurs in noisy environments ${ }^{13,14}$. Finally, there is the sensory seeker, this pattern is characterized by presenting a high sensory threshold but employs strategies of active self-regulation, that is, individuals seek and crave sensory stimulation in an unusual way, showing an insatiable desire to increase the intensity of the stimulus ${ }^{13,14}$.
According to the model proposed by Winnie Dunn, this allowed him to design the sensorial profile questionnaire; the internal consistency level of the instrument is 0.97 Cronbach's Alpha and presents versions in English, Spanish, and Chinese. The application time of the instrument is approximately $45 \mathrm{~min}$; this questionnaire must be applied by the occupational therapists to the caregivers and nurses of the children or on the contrary observations are made by the professional in charge so that it can be completed ${ }^{15}$.

Previous studies have reported that there are multiple mechanisms through which sensory disturbances at an early age in children with ASD enter a cascade of social deficits that affect functionality in this type of population. In the United States, they have identified that $95 \%$ of children with ASD present some degree of diffusion in sensory processing, specifically altered sensory systems are often auditory, visual, and tactile ${ }^{16,17}$. Studies conducted in children with TD have reported a prevalence of sensory processing disorders between 14.3 and $28.6 \%$, which affected their school activities and activities of daily living ${ }^{18}$.

The one developed by Mailloux and Miller-Kuhaneck ${ }^{19}$ is one of the few studies that have made comparisons of the sensory profile; those that compared the characteristics of sensory processing among a group of children living in the United States (between 5 and 8 years of age) with and without ASD. In this study, 84 children and their parents participated; the results show that both groups behave differently in all the subscales that evaluate the sensory processing, in the case of the group with ASD, the behaviors they present are significantly related to the degree of severity in the symptoms of autism.

The authors agree that the sensory profile evaluations allow a better understanding of the sensory deficit and thus provide the possibility of generating therapeutic measures according to the needs of each individual, due to the heterogeneous characteristics that occur in each child with ASD and DT ${ }^{19,20}$. So far, most of the research conducted in this area has been in the United States and Europe; however, there is a low level of scientific evidence in South America about the variety of sensory responses that can be presented in the groups to be studied ${ }^{21}$. Despite the high impact that this type of alterations generates on the functional performance of children with ASD and DT, no comparative studies have been reported in Latin America. Obtaining this type of data is essential to identify the differences and similarities that may occur in both groups, in this sense those factors influence the timely detection of sensory alterations, which generate a negative impact on the 
Table 1. Interpretation of results from the Winnie Dunn categories.

\begin{tabular}{|l|l|l|l|}
\hline $\begin{array}{l}\text { Sensory processing } \\
\text { patterns }\end{array}$ & $\begin{array}{l}\text { Less than other/much less than } \\
\text { others }\end{array}$ & $\begin{array}{l}\text { Just like the majority of } \\
\text { others }\end{array}$ & $\begin{array}{l}\text { More than others/much more than } \\
\text { others }\end{array}$ \\
\hline Seeking & $\begin{array}{l}\text { May not look for enough sensory } \\
\text { information to sustain successful } \\
\text { participation }\end{array}$ & $\begin{array}{l}\text { Use sensory stimuli to gather } \\
\text { the information necessary for } \\
\text { their participation }\end{array}$ & $\begin{array}{l}\text { Can search for sensory information } \\
\text { so excessively or disruptively that it } \\
\text { interferes with participation }\end{array}$ \\
\hline Avoiding & $\begin{array}{l}\text { The detection of the sensory } \\
\text { stimulus necessary for participation } \\
\text { may fail }\end{array}$ & $\begin{array}{l}\text { Handles sensory information } \\
\text { to get only the amount needed } \\
\text { for participation }\end{array}$ & $\begin{array}{l}\text { Can become so overwhelmed by } \\
\text { sensory information that it interferes } \\
\text { with participation }\end{array}$ \\
\hline Sensitivity & $\begin{array}{l}\text { May not detect the sensory input } \\
\text { particularly necessary to sustain } \\
\text { participation }\end{array}$ & $\begin{array}{l}\text { Detects the sensory input that } \\
\text { allows participation }\end{array}$ & $\begin{array}{l}\text { Maybe so distracted by sensory } \\
\text { information that it interferes with } \\
\text { participation }\end{array}$ \\
\hline Registration & $\begin{array}{l}\text { Can observe sensory stimuli that } \\
\text { are not useful for participation }\end{array}$ & $\begin{array}{l}\text { Observes enough sensory } \\
\text { stimuli that allow participation }\end{array}$ & $\begin{array}{l}\text { May lose the sensory information } \\
\text { necessary for participation }\end{array}$ \\
\hline
\end{tabular}

Reference source: sensory profile Winnie Dunn

performance of school activities and of daily life in both groups. Therefore, it is considered necessary to analyze the impact of this type of deficit in age groups or development status because it directly affects an effective intervention. The main objective of this study was to determine and compare the sensory profile in a sample of children between 3 and 12 with ASD and TD through the Sensory Profile of Winnie Dunn.

\section{Methods}

A transversal descriptive study of correlation type was carried out where 59 participants were selected through a non-probabilistic sampling for convenience, in this case, 28 children with TD and 31 children with ASD met the following inclusion criteria; boys and girls between the ages of 3 and 12 years, with diagnosis confirmed by a neuropediatric of ASD, in the case of children with TD they should not have presented any warning sign during their psychomotor development; for both groups of participants the parents had to sign the informed consent.

\section{Materials}

To fulfill the objective of the research, the sensory profile of Winnie Dunn Spanish version was applied to 59 participants, this questionnaire is divided into three sections that evaluate; the sensory system (visual, auditory, oral, proprioceptive, and vestibular) together with the sensory patterns (Search, avoidance, low register, and sensitivity) and behavior (behavior, attention, and social emotions). It contains 125 questions related to the sensory aspect and has as options of answers: almost always (5), frequently (4), half of the time (3), occasionally (2), almost never (1), and not applicable (0), for the qualification, the sum of the answers to each question was made according to the evaluated item, later this score is compared with the scales that go according to each item and that in this case indicates the categories that the child is in; less than other/much less than others, just like the majority of other and much more than/more than other, each of the above presented an interpretation that indicated the sensory characteristics presented by children with ASD and DT evaluated (Table 1).

\section{Process}

The researchers conducted a review of the literature based mainly on the theory described by the Occupational Therapists Jean Ayres and Winnie Dunn, analyzing the sensory behaviors within the areas of action in which individuals develop sensory level.

Subsequently, the evaluators went to the educational institutions and rehabilitation centers located between the cities of Barranquilla and Valledupar, where the risks, procedures, and benefits of the investigation were shared with parents, managers, therapists, caregivers, and teachers. The informed consent form was given to the parents who accepted their children's participation in the study. Data collection by occupational therapists was carried out during the months of June and July of 2018, through the technique of direct observation and interviews with parents, the evaluators were trained to perform the registration of the Winnie Dunn format. In addition, the professionals in charge of the evaluation have 6 years of experience in the assessment and intervention of this population. 
As part of the evaluations carried out, each therapist performed the respective screening according to the sensory behaviors reported in the instrument; finally, the information collected was entered into a database designed in Excel version 2010 and was later exported to the statistical software SPSS version 20.

\section{Statistic analysis}

According to the information collected, an analysis of the proportional distribution of the following variables was carried out; sociodemographic characteristics, sensory processing patterns, processing, and behavior system; later to identify whether the variables of the sensory profile were parametric or non-parametric, the Kolmogorov-Smirnov statistical test was applied in both groups (DT-TEA); finally, to establish the differences and similarities of both groups about the sensory profiles, the student's t-test for independent samples was applied, accepting a significant value of $p<0.05$.

\section{Results}

At the level of sociodemographic characteristics, the following was observed; there is a greater number of male participants in both the ASD group and DT group, $64.5 \%$ of the ASD group and $100 \%$ of the group with TD are in school, the average age of the ASD participant is $6.97 \pm$ 2.93 and in children with TD was $6.61 \pm 3.29$ (Table 2).

Regarding the patterns of sensory processing evaluated through the sensory profile of Winnie Dunn, in the search pattern, it was observed that $45.2 \%$ of the group with ASD is within the response category more than other/much more than other. It means that children with ASD can search for sensory information so much that it interferes with participation, while $64.3 \%$ of the group with DT is in the category just like majority than others, which means that they use various sensory stimuli to gather the information necessary for active participation (Table 3).

Regarding the pattern of avoidance, it is confirmed that $54.8 \%$ of children with ASD are within the score more than other/much more than other, which indicates that they can be overwhelmed with sensory information to such an extent that interferes with their participation. As for children with TD, 60, $7 \%$ are in the category of just like the majority of others (Table 3 ).

In the sensitivity pattern within the obtained results it was evidenced that $64.5 \%$ of the group with ASD are within the score more than other/much more than other which indicates that they can be distracted with both the non-organized sensory information. On the other
Table 2. Sociodemographic characteristics of the groups studied.

\begin{tabular}{|l|c|c|}
\hline \multirow{2}{*}{ Sociodemographic characteristics } & \multicolumn{2}{|c|}{ Frequency (\%) } \\
\cline { 2 - 3 } & ASD & DT \\
\hline $\begin{array}{l}\text { Gender } \\
\text { Female } \\
\text { Male }\end{array}$ & $5(16.1)$ & $11(39.3)$ \\
\hline $\begin{array}{l}\text { Schooled } \\
\text { Yes } \\
\text { No }\end{array}$ & $26(83.9)$ & $17(60.7)$ \\
\hline
\end{tabular}

Reference source: sensory profile Winnie Dunn. ASD: autism spectrum disorder; DT: typical development

hand, $89.3 \%$ of the children with DT are in the "just like the majority of others" category, that is, they detect the sensory stimuli that allow their participation.

In the registration pattern, both the group with ASD and that of DT were rated within the category just like the majority of others, it means, they perceive the amount of stimuli sufficient for correct participation. The results and the comparisons revealed that there are significant differences between the group with ASD and the group with DT $(p=0.00)$ (Table 3$)$. In each of the evaluated patterns, the TEA group shows a trend of higher values $(41.77 \pm 18.72)$ compared to the measurement of the DT group $(24.500 \pm 8.87)$ (Table 4).

At the level of auditory sensory processing systems, $74.2 \%$ of children with ASD and $64.3 \%$ of children with TD are within the response category just like the majority of others, in sensory processing visual $48.4 \%$ of the group with ASD and $42.9 \%$ of children with TD are in the category just like the majority of others. However, 53.5\% of children with TD and $38.7 \%$ of ASD are in the less than other/much less than other category, which indicates that they are below the response threshold established by Dunn. In tactile sensory processing, $51.7 \%$ of children with ASD are in the more than other/much more than other category, with this high threshold giving rise to determining that there is greater tactile defensibility that bursts into their behavior, whereas the group with DT $67.9 \%$ of children is in the category just like the majority than other (Table 5). Otherwise, in both groups, both TEA and DT are in the category just like the majority than other at the level of the vestibular, proprioceptive, and gustatory systems. Regarding the sensory processing systems evaluated through the Winnie Dunn sensory profile, the results and comparisons revealed that there are significant differences between the group with ASD and the group with DT in each of the systems $(p=0.00)$ except in the visual system $(p=0.31)$ (Table 6$)$. 
Table 3. Mean difference in sensory processing patterns

\begin{tabular}{|c|c|c|c|c|}
\hline Patterns of sensory processing & Groups & Media (SD) & Differences of medias & $\mathbf{p}$ \\
\hline \multirow[t]{2}{*}{ Seeking } & ASD & $42.290 \pm 19.03$ & 13.32 & $0.00^{*}$ \\
\hline & DT & $28.964 \pm 4.41$ & & \\
\hline \multirow[t]{2}{*}{ Avoiding } & ASD & $48.77 \pm 16.71$ & 19.45 & $0.00^{*}$ \\
\hline & DT & $29.321 \pm 14.48$ & & \\
\hline \multirow[t]{2}{*}{ Sensitivity } & ASD & $45.806 \pm 15.21$ & 17.09 & $0.00^{*}$ \\
\hline & DT & $28.714 \pm 9.24$ & & \\
\hline \multirow[t]{2}{*}{ Observation } & ASD & $41.774 \pm 18.62$ & 17.27 & $0.00^{*}$ \\
\hline & DT & $24.500 \pm 8.87$ & & \\
\hline \multirow[t]{2}{*}{ Auditory } & ASD & $19.387 \pm 6.95$ & 5.78 & $0.00^{*}$ \\
\hline & DT & $13.607 \pm 6.78$ & & \\
\hline \multirow[t]{2}{*}{ Visual } & ASD & $10.25 \pm 6.11$ & 1.4 & 0.31 \\
\hline & DT & $8.857 \pm 4.24$ & & \\
\hline \multirow[t]{2}{*}{ Touch } & ASD & $22.419 \pm 9.99$ & 6.91 & $0.00^{*}$ \\
\hline & DT & $15.500 \pm 7.54$ & & \\
\hline \multirow[t]{2}{*}{ Movement } & ASD & $17.613 \pm 8.88$ & 6.75 & $0.00^{*}$ \\
\hline & DT & $10.857 \pm 5.83$ & & \\
\hline \multirow[t]{2}{*}{ Body position } & ASD & $12.516 \pm 9.09$ & 5.69 & $0.00^{*}$ \\
\hline & DT & $6.812 \pm 5.60$ & & \\
\hline \multirow[t]{2}{*}{ Oral } & ASD & $20.065 \pm 9.68$ & 5.38 & $0.02^{*}$ \\
\hline & DT & $14.679 \pm 8.16$ & & \\
\hline \multirow[t]{2}{*}{ Behavioral } & ASD & $22.387 \pm 9.14$ & 7.99 & $0.00^{*}$ \\
\hline & DT & $14.393 \pm 6.59$ & & \\
\hline \multirow[t]{2}{*}{ Socialemotional } & ASD & $34.613 \pm 14.7$ & 13.68 & $0.00^{*}$ \\
\hline & DT & $20.929 \pm 13.85$ & & \\
\hline \multirow[t]{2}{*}{ Attention } & ASD & $29.903 \pm 10.39$ & 14.54 & $0.00^{*}$ \\
\hline & DT & $15.357 \pm 7.09$ & & \\
\hline
\end{tabular}

Reference source: sensory profile de Winnie Dunn. ${ }^{*} p<0.05$ Significant differences. ASD: autism spectrum disorder; DT: typical development; SD: standard deviation.

Regarding the proportional distribution measures, it was identified that at the behavioral level, $51.7 \%$ of children with ASD are in the category more than other/much more than others, this occurs in the same way in the items of attention and socioemotional relationships, giving rise to the responses or sensory challenges directly affect the performance in the activities of daily life, generating behaviors that are misinterpreted as not very adaptive. However, the group with DT is within the response category just like the majority of others, that is, sensory processing systems may not affect the behavior of this population
(Table 5). Both groups present significant differences in each of the variables $(p=0.00)$, the group with ASD has a tendency to score above the mean at the behavioral level (22.387 \pm 9.14$)$, socioemotional relationships (34.613 \pm 14.7$)$, and attention (29.903 \pm 10.39) with respect to the group of children with TD (Table 4).

\section{Discussion}

Based on the results obtained in this research, we identified within the sociodemographic characteristics 
Table 4. Percentage distribution of the processing patterns of the groups studied

\begin{tabular}{|c|c|c|}
\hline \multirow[t]{2}{*}{ Patterns of sensory processing } & \multicolumn{2}{|c|}{ Frequency (\%) } \\
\hline & ASD & DT \\
\hline $\begin{array}{l}\text { Seeking } \\
\text { More than other/much more than other } \\
\text { Less than other/much less than other } \\
\text { Just like the majority than others }\end{array}$ & $\begin{array}{l}14(45.2) \\
4(12.9) \\
13(41.9)\end{array}$ & $\begin{array}{c}3(10.7) \\
7(25) \\
18(64.3)\end{array}$ \\
\hline $\begin{array}{l}\text { Avoiding } \\
\text { More than other/much more than other } \\
\text { Less than other/much less than other } \\
\text { Just like the majority than others }\end{array}$ & $\begin{array}{c}17(54.8) \\
0 \\
14(45.2)\end{array}$ & $\begin{array}{c}] \\
4(14.3) \\
7(25) \\
17(60.7)\end{array}$ \\
\hline $\begin{array}{l}\text { Sensitivity } \\
\text { More than other/much more than other } \\
\text { Less than other/much less than other } \\
\text { Just like the majority than others }\end{array}$ & $\begin{array}{c}20(64.5) \\
2(6.5) \\
9(29)\end{array}$ & $\begin{array}{c}1(3.6) \\
2(7.1) \\
25(89.3)\end{array}$ \\
\hline $\begin{array}{l}\text { Registration } \\
\text { More than other/much more than other } \\
\text { Less than other/much less than other } \\
\text { Just like the majority than others }\end{array}$ & $\begin{aligned} 12 & (38.7) \\
2 & (6.5) \\
17 & (54.8)\end{aligned}$ & $\begin{array}{c}5(17.9) \\
0 \\
23(82.1)\end{array}$ \\
\hline
\end{tabular}

Reference source: sensory profile Winnie Dunn. ASD: autism spectrum disorder; DT: typical development.

that the majority of the population with ASD evaluated is male, with an average age of 6 years; they are in school and with therapeutic intervention. These data coincide with that reported by the Centers for Disease Control of Atlanta with acronyms $\mathrm{CDC}^{3}$ where it states that one in every 59 children between the ages of 6 and 8 years have been diagnosed with ASD with a 4 times higher tendency in man that in women, likewise, $95 \%$ of children diagnosed with ASD resident in the United States have been included in special education programs.

At the level of sensory processing patterns, we observed that both groups behave differently in the patterns of search, avoidance, sensitivity, and observation. The group with ASD presented alterations in the aforementioned patterns compared to the group with DT, which presented a performance according to age and condition in each of them, these results coincide with the reported by Brown et al. ${ }^{22}$, who in the same way compared a group with ASD and a group with DT and found that there were significant differences in those patterns ( $p \leq 0.017$ ), the group with ASD showed alterations in sensory processing. Similar results were reported in the study conducted by Brockevelt, et al. ${ }^{23}$ In the United States in a sample of 21 children with ASD between the ages of 3 and 9 years, also reported that there are significant differences between the groups with ASD and DT in each of the sensory patterns $(p<0.001)$. Little et al. ${ }^{24}$ presented several studies
Table 5. Percentage distribution of the sensory processing systems of the groups

\begin{tabular}{|c|c|c|}
\hline \multirow[t]{2}{*}{ Sensorial processing system } & \multicolumn{2}{|c|}{ Frequency $(\%)$} \\
\hline & ASD & DT \\
\hline $\begin{array}{l}\text { Auditory processing } \\
\text { More than other/much more than other } \\
\text { Less than other/much less than other } \\
\text { Just like the majority than other }\end{array}$ & $\begin{array}{c}6(19.4) \\
2(6.5) \\
23(74.2)\end{array}$ & $\begin{array}{c}10(35.7) \\
0 \\
18(64.3)\end{array}$ \\
\hline $\begin{array}{l}\text { Visual processing } \\
\text { More than other/much more than other } \\
\text { Less than other/much less than other } \\
\text { Just Like the majority than other }\end{array}$ & $\begin{array}{c}4(12.9) \\
12(38.7) \\
15(48.4)\end{array}$ & $\begin{array}{c}1(3.6) \\
15(53.5) \\
12(42.9)\end{array}$ \\
\hline $\begin{array}{l}\text { Touch processing } \\
\text { More than other/much more than other } \\
\text { Less than other/much less than other } \\
\text { Just like the majority than other }\end{array}$ & $\begin{array}{c}16(51.7) \\
1(3.2) \\
14(45.2)\end{array}$ & $\begin{array}{c}6(21.4) \\
3(10.7) \\
19(67.9)\end{array}$ \\
\hline $\begin{array}{l}\text { Vestibular processing } \\
\text { More than other/much more than other } \\
\text { Less than other/much less than other } \\
\text { Just like the majority than other }\end{array}$ & $\begin{array}{c}14(45.1) \\
2(6.4) \\
15(48.4)\end{array}$ & $\begin{array}{c}3(10.7) \\
5(17.9) \\
20(71.4)\end{array}$ \\
\hline $\begin{array}{l}\text { Proprioceptive processing } \\
\text { More than other/much more than other } \\
\text { Less than other/much less than other } \\
\text { Just like the majority than other }\end{array}$ & $\begin{array}{c}9(29) \\
6(19.4) \\
16(51.6)\end{array}$ & $\begin{array}{c}1(3.6) \\
8(28.6) \\
19(67.9)\end{array}$ \\
\hline $\begin{array}{l}\text { Gustatory processing } \\
\text { More than other/much more than other } \\
\text { Less than other/much less than other } \\
\text { Just like the majority than other }\end{array}$ & $\begin{array}{c}11(35.5) \\
1(3.2) \\
19(61.3)\end{array}$ & $\begin{array}{c}2(7.1) \\
4(14.3) \\
22(78.6)\end{array}$ \\
\hline
\end{tabular}

Reference source: sensory profile Winnie Dunn. ASD: autism spectrum disorder; DT: typical development.

Table 6. Percentage distribution of behavior of the groups studied

\begin{tabular}{|c|c|c|}
\hline \multirow[t]{2}{*}{ Behavior } & \multicolumn{2}{|c|}{ Frequency (\%) } \\
\hline & ASD & DT \\
\hline More than other/much more than other & $16(51.7)$ & $1(3.6)$ \\
\hline Less than other/much less than other & $1(3.2)$ & $5(17.9)$ \\
\hline Just like the majority than other & $14(45.2)$ & $22(78.6)$ \\
\hline \multirow{4}{*}{$\begin{array}{l}\text { Socialemotional relationship } \\
\text { More than other/much more than other } \\
\text { Less than other/much less than other } \\
\text { Just like the majority than other }\end{array}$} & & \\
\hline & $17(54.8)$ & $5(17.9)$ \\
\hline & $1(3.2)$ & $6(21.4)$ \\
\hline & $13(41.9)$ & $17(60.7)$ \\
\hline \multicolumn{3}{|l|}{ Attention } \\
\hline More than other/much more than other & $21(67.8)$ & $2(7.1)$ \\
\hline Less than other/much less than other & $1(3.2)$ & $4(14.3)$ \\
\hline Just like the majority than other & $9(29)$ & $22(78.6)$ \\
\hline
\end{tabular}

Reference source: sensory profile Winne Dunn. ASD: autism spectrum disorder DT: typical development.

under the same approach, which state that the sensory patterns of the groups studied are different.

Likewise, the group with ASD presented higher scores with respect to the DT group at the level of the 
patterns and sensory processing system; each of the groups presented significant differences. Those results coincide with the study carried out by Linde et al. ${ }^{25}$, in the USA that affirms that the scores of the ASD are always superior in each of the patterns of sensory processing with respect to the DT. However, in the study conducted by Brown et al. ${ }^{22}$ and Brockevelt et al. ${ }^{23}$ found that the group diagnosed with ASD residing in Australia and another group of children with the same condition residing in the United States had significantly lower scores in comparing the group of children with TD in each of the sensory processing patterns, the sensory patterns were altered in all the groups studied with ASD.

The study conducted by Tomchek and Dunn ${ }^{26}$ in the USA with a sample of 281 children with and without ASD, partially supports the results obtained, stating that both groups had significant differences in each of the systems (visual, auditory, tactile, gustatory, vestibular, and proprioceptive) $(p=0.00)$. Cervera et al. ${ }^{27}$ also performed a study in a sample of children with ASD and DT in Spain, in this case, they reported that statistical comparisons revealed significant differences between both groups $(p=0.00)$.

Regarding the level of the auditory sensory processing system, both the group with ASD and the group with DT, register a threshold within the typical sensory parameters, that is, their performance is in accordance with the chronological age, those results are contrary to the exposed by Tomchek and Dunn ${ }^{26}$ where $77.6 \%$ of children with ASD present alterations in this system and $87.8 \%$ of children with SD have a performance within the range. Similarly, in Canada, in a study conducted by Nadon et al. ${ }^{28}$, I observed that $55.8 \%$ of children with ASD presented alterations of the auditory type that affect their daily functioning.

In the visual system, DT children presented a low response threshold compared to children with ASD. The last thing coincides with the study carried out by Nadon et al. ${ }^{28}$ and Tomchek and Dunn ${ }^{26}$. Where children with ASD present a typical performance score and children with SD were below the scores established by the Winnie Dunn scale.

In relation to the tactile system, the majority of the group with ASD tended to have a high response threshold in proportion to the group with DT that presented a performance within the typical range. This coincides with the study carried out by Linde et al. ${ }^{25}$, which reports that $60.1 \%$ of children with ASD present alterations in this system.
In the gustatory system, the majority of children with ASD had a higher response threshold compared to children with DT who presented a performance according to age. These results are related to the study developed by Dunn ${ }^{12}$ and Al-Heizan et al. ${ }^{29}$ where they also reported deficiencies in this system, specifically $54.1 \%$ of children with ASD evaluated, parents reported the intake of only some foods, in the case of children with DT their food intake was wider. In relation to the behavioral item, it was identified that the majority of the group with ASD reflect poorly adapted behaviors as consequences of faults in patterns and sensory systems. This coincides with the study carried out by Cervera et al. ${ }^{27}$ and Little et al. ${ }^{24}$ it was identified that the majority of the group with ASD presents alterations at the level of social participation due to deficiencies in the sensory system, children with DT show adaptive responses according to the expected performance for their age.

\section{Conclusions}

From this study, we can infer that there are differences between the sensory profiles of the compared groups as they were DT and ASD, in addition, the sensory deficit prevalence is higher in ASD than in children with TD. In this case, it is of vital importance the intervention of these deficiencies through sensory integration programs that allow a foster adaptive response by children with ASD. It is necessary that this type of sensory modulation be provided at home, school, and in the therapeutic environment for each one of the professionals in charge of the intervention in this type of population.

Despite the limitations that some professionals have to certify themselves as sensory integrators, we believe that this work is a first step to examine in a sample of Colombian children with and without ASD dysfunctions in sensory integration, and therefore raise awareness about the different difficulties that this group usually faces.

\section{Ethical disclosures}

Protection of people and animals. The authors declare that the procedures followed to conform to the ethical standards of the responsible human experimentation committee and in accordance with the World Medical Association and the Declaration of Helsinki. 
Confidentiality of the data. The authors declare that they have followed the protocols of their work center on the publication of patient data.

Right to privacy and informed consent. The authors have obtained the informed consent of the patients and/or subjects referred to in the article. This document is in the possession of the correspondence author.

\section{Conflicts of interest}

The authors declare that there are no relevant conflicts of interest.

\section{Funding}

The particular sources of financing for this scientific report was Foundart Academy Headquarters, Miami, United States.

\section{References}

1. Asociación Americana de Psiquiatría Manual Estadístico de Trastornos Mentales DSM V. Washington D.C., Estados Unidos: Asociación Americana de Psiquiatría; 2013.

2. Grzadzinski R, Huerta M, Lord C. DSM-5 and autism spectrum disorders (ASDs): an opportunity for identifying ASD subtypes. Mol Autism. 2013;4:12.

3. Centro de Control de Enfermedades de Atlanta. (CDC). Data and Statistics. Available from: https://www.cdc.gov/ncbddd/autism/data.html. Last accesed [2018 Dec 18]

4. Omairi C. Autismo: perspectivas no Dia a Dia. Brazil: Ithala Editora; 2014

5. Castillejos L, Rivera R. Asociación entre el perfil sensoria, el funcionamiento de la relación cuidador niño y el desarrollo psicomotor a los tres años de edad. Salud Ment. 2009;32:231-9.

6. Román-Oyola R, Reynolds S. Prevalence of sensory modulation disorder among Puerto Rican preschoolers: an analysis focused on socioeconomic status variables. Occup Ther Int. 2013;20:144-54.

7. Irizabal IP. La Integración Sensorial en la Etapa de Educación Infantil. (Tesis de Maestría). España: Universidad de Catabria; 2015.

8. Ayres J. La Integración Sensorial en el Niño. Ciudad de México. México: Trillas; 1998

9. Ramírez DB. Caracteristicas del Procesamiento Sensorial y su Relación con la Generación de Dificultades de Aprendizaje en Niños Escolares con Epilepsia Entre los 7 y 10 Años, Bogotá (Colombia). Tesis de Maestria Neurociencias. Bogotá: Universidad Nacional de Colombia; 2016.
10. Ayres AJ. Cluster analyses of measures of sensory integration. Am J Occup Ther. 1977;31:362-6.

11. Miller LJ, Anzalone ME, Lane SJ, Cermak SA, Osten ET. Concept evolution in sensory integration: a proposed nosology for diagnosis. Am J Occup Ther. 2007;61:135-40.

12. Dunn, W. The sensory profile: a discriminating measure of sensory processing in daily life. Vol. 20. Sensory Integration Special Interest Section Newsletter. 1997. p. 1-3.

13. Román RO. Comprendiendo la nosología de los desórdenes de procesamiento sensorial: Parte I. Conexión. 2013;2:2-4

14. Romero JS. Diferencias en el procesamiento sensorial entre niños/as pretérmino y a término: el papel del terapeuta ocupacional. Rev Chil Ter Ocup. 2016;16:47-56.

15. Dunn W. Sensory Profile 2: users Manual. $2^{\text {nd }}$ ed. Psych Corporation; 2014. p. 268.

16. Pérez-Robles R, Doval E, Jané MC, et al. The role of sensory modulation deficits and behavioral symptoms in a diagnosis for early childhood. Child Psychiatry Hum Dev. 2013;44:400-11.

17. Thye MD, Bednarz HM, Herringshaw AJ, Sartin EB, Kana RK. The impact of atypical sensory processing on social impairments in autism spectrum disorder. Dev Cogn Neurosci. 2018;29:151-67.

18. Delgado-Lobete L, Montes R, Rodriguez S. Prevalencia de trastorno del procesamiento sensorial en niños españoles. Resultados preliminares y comparación entre herramientas de diagnóstico. TOG (ACoruña). 2016;13:19

19. Mailloux Z, Miller-Kuhaneck $H$. From the desk of the guest editors evolution of a theory: how measurement has shaped Ayres sensory integra${ }^{\circledR}$. Am J Occup Ther. 2014:68:495-99.

20. Gutiérrez JF, Chang M, Blanche El. Funciones sensoriales en niños menores de tres años dianosticados con trastornos del espectro autista. Rev Chil Ter Ocup. 2016;16:89-98.

21. Orekhova EV, Tsetlin MM, Butorina AV, et al. Auditory cortex responses to clicks and sensory modulation difficulties in children with autism spectrum disorders (ASD). PLoS One. 2012;7:e39906.

22. Brown $\mathrm{T}$, Leo M, Austin D. Discriminat validity of the sensory profile in Australian children with austism spectrum disorder. Phys Occup Ther Pediatr. 2008:28:253-66.

23. Brockevelt BL, Nissen R, Schweinle WE, Kurtz E, Larson KJ. A comparison of the sensory profile scores of children with autism and an age and gender-matched sample. S D Med. 2013;66:459, 461, 463-5.

24. Little LM, Dean E, Tomchek S, Dunn W. Sensory processing patterns in autism, attention deficit hyperactivity disorder, and typical development. Phys Occup Ther Pediatr. 2018;38:243-54.

25. Linde JV, Franzsen D, Ashton PB. The sensory profile: comparative analysis of children with specific language impairment, ADHD and Autism. S Afr J Occup Ther. 2013;43:34-40.

26. Tomchek SD, Dunn W. Sensory processing in children with and without autism: a comparative study using the short sensory profile. Am J Occup Ther. 2007;61:190-200

27. Cervera S, Fernández Al, Cerezuela P, Puchol FI, Llongo EH. Relación entre el procesamiento sensorial y la severidad de la sintomatología en una muestra de niños con TEA. Int J Dev Educ Psychol. 2014; 3:353-61.

28. Nadon G, Feldman DE, Dunn W, Gisel E. Association of sensory processing and eating problems in children with autism spectrum disorders. Autism Res Treat. 2011;2011:541926.

29. Al-Heizan MO, AlAbdulwahab SS, Kachanathu SJ, Natho M. Sensory processing dysfunction among Saudi children with and without autism. J Phys Ther Sci. 2015;27:1313-6. 